\title{
Alcohol Dehydrogenase
}

National Cancer Institute

\section{Source}

National Cancer Institute. Alcohol Dehydrogenase. NCI Thesaurus. Code C16272.

Members of this enzyme family metabolize a wide variety of substrates, including ethanol, retinol, other aliphatic alcohols, hydroxysteroids, and lipid peroxidation products. 